\title{
Neonatal Intramuscular Injection of Plasmid DNA Encoding GLP-1 Reduces Serum Insulin Level and Modifies Skeletal Muscle Myosin Heavy Chain Composition in Adult Rats
}

\author{
L. WANG, F. GUO, S. WEI, R. ZHAO
}

Key Laboratory of Animal and Biochemistry, Nanjing Agricultural University, Nanjing, China

Received May 5, 2009

Accepted August 13, 2009

On-line November 20, 2009

\begin{abstract}
Summary
To test the hypothesis that neonatal GLP-1 exposure may program myosin heavy chain (MyHC) composition in adult skeletal muscle, two-day-old rats were transfected intramuscularly with vacant vector plasmid (VP), or recombinant plasmid expressing secretory GLP-1 at the doses of $60 \mu \mathrm{g}$ (LG) and $120 \mu \mathrm{g}(\mathrm{HG})$, respectively. Expression of GLP-1 mRNA was detected in muscles of both LG and HG rats 7 days after transfection, with more abundant GLP-1 transcript seen in LG rats. In accordance with the GLP-1 expression, LG rats demonstrated more significant responses to neonatal GLP-1 exposure. Small yet significant growth retardation was observed in LG rats, which is accompanied with significantly reduced serum insulin concentration at 8 weeks of age compared to VP rats. The responses of skeletal muscle were dependent on muscle type. Significant increase of PGC-1a and GLUT4 mRNA expression was detected in soleus of LG rats, whereas a MyHC type switch from II B to I was seen in gastrocnemius. These results indicate that neonatal exposure of healthy pups to ectopic GLP-1 causes growth retardation with decreased serum insulin as well as muscle type-dependent modifications in MyHC type composition and metabolic gene expression in adult rats.
\end{abstract}

\section{Key words}

GLP-1 • Suckling • Skeletal muscle • Insulin • Myosin heavy chain (MyHC)

\section{Corresponding author}

R. Zhao, Key Laboratory of Animal Physiology and Biochemistry, Nanjing Agricultural University, Nanjing 210095, P. R. China. Fax: 00862584398669. E-mail: zhao.ruqian@gmail.com

\section{Introduction}

Glucagon-like peptide (GLP-1) is produced through posttranslational processing of proglucagon in intestinal L-cells in response to nutrient ingestion (Aulinger et al. 2007), and is regarded as a potential agent for the treatment of type 2 diabetes, mainly due to its insulinotropic capacity and insulinomimetic actions (Kashima et al. 2001). Impaired GLP-1 secretion was observed in patients with type 2 diabetes (Toft-Nielsen $e t$ al. 2001). Administration of GLP-1 receptor (GLP-1R) agonists on diabetic $(\mathrm{db} / \mathrm{db})$ mice or a partial pancreatectomy rat model of type 2 diabetes could enhance $\beta$-cell proliferation, increase $\beta$-cell mass and attenuate the development of diabetes (Xu et al. 1999, Kim et al. 2003).

Besides its immediate effects, neonatal GLP-1 exposure has programming effects on adult pancreatic functions. Daily injection of GLP-1 or its long-acting analog exendin-4 (Ex-4) from day 2 to day 6 after birth led to improved $\beta$-cell mass and glucose homeostasis in adult GK rats, a genetic model of type 2 diabetes (Tourrel et al. 2002). Activation of GLP-1R signal transduction pathways by Ex-4 injection in the critical neonatal period is sufficient for sustained improvement in $\beta$-cell mass and function in adult intrauterine growth retarded (IUGR) rats (Stoffers et al. 2003). Therefore, GLP-1 is considered as a promising agent not only for the treatment, but also for the prevention of type 2 diabetes in susceptible individuals. As all the studies concerning the programming effects of GLP-1 or its analogs were carried out in diabetic or predisposed diabetic susceptible animal 
models, it is unknown whether and how neonatal exposure of high GLP-1 may program the adult glucose homeostasis in healthy animals.

Moreover, extrapancreatic tissues such as liver and skeletal muscle have been implicated to be potential targets for GLP-1 action. For instance, GLP-1 was found to stimulate glycogen synthesis in human myocytes (Luque et al. 2002) and hepatic glycogen storage in mice (Knauf et al. 2005). Skeletal muscles account for almost $50 \%$ of the total body weight and their metabolic characteristics are closely related to the glucose homeostatic status (Sinacore and Gulve 1993). Furthermore, skeletal muscle has been shown to be one of the major target tissues for neonatal metabolic programming (Holness et al. 2000). The responses of skeletal muscles to nutritional or endocrine interventions in early life seem to be muscle type-dependent. A maternal low-protein diet during mid-pregnancy reduced total number and density of fast glycolytic fibers in soleus muscle of 4-week-old rats, whereas in gastrocnemius muscle, the density of slow oxidative fibers was reduced (Mallinson et al. 2007). Up to now, no data is available about neonatal programming effect of GLP-1 on adult myofiber type characteristics of different muscle types.

In order to circumvent the rapid turnover of exogenously injected GLP-1, we constructed a recombinant vector expressing secretory GLP-1, and transfected it intramuscularly in two-day-old rat pups to achieve continuous ectopic expression of GLP-1 during suckling period. Growth performance was monitored up to 8 weeks of age when the animals were sacrificed to determine insulin secretion, glucose concentration, as well as profiles of myosin heavy chain (MyHC) types and expression of metabolism-related genes in two types of skeletal muscle - soleus and gastrocnemius.

\section{Methods}

\section{Plasmid construction}

The recombinant plasmid expressing secretory GLP-1, sig-glp-1-pcDNA3, was constructed containing signal peptide coding sequence and full length cDNA of rat glp-1. Briefly, upstream signal peptide coding sequence including restriction site Hind III (P1) and downstream signal peptide coding sequence (P2) were synthesized as two partly complementary single strands DNA. Using asymmetrical primer/template, frontal P1P2 was synthesized in vitro. Rat GLP-1 cDNA (P3P4) including part of P2 was cloned by RT-PCR with specific primers including restriction site (BamH I). Finally, P1P4 (sig-glp-1) was synthesized with P1P2 and P3P4 by mean of asymmetrical primer/template (Fig. 1). Sequences of P1P4 were analyzed using special software to confirm that splice site of signal peptide can still be identified after recombination. P1P4 (sig-glp-1) was inserted into the multiple cloning site of the pcDNA3 expression vector (sig-glp-1-pcDNA3). The empty pcDNA3 plasmid was used as a control. Plasmids were transformed in DH5 $\alpha$, extracted using Tiangen EndoFree plasmid kits. Purified DNA was dissolved in phosphate-buffered saline $(\mathrm{pH}$ 7.4) and the quantity and quality were assessed by spectrophotometry.
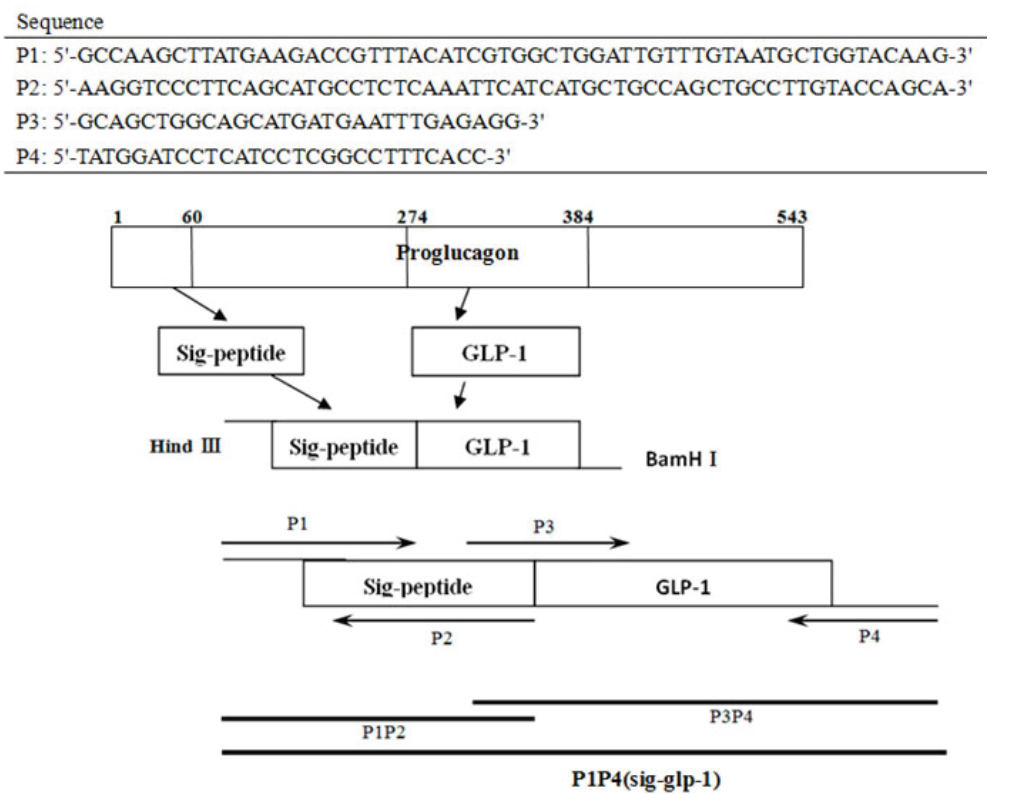

Fig. 1. In vitro synthesis of DNA insert containing signal peptide coding sequence and full length CDNA of rat glp-1 (sig-glp-1). 


\section{Rats and in vivo electroporation}

Adult male and female Wistar breeder rats were purchased from Shanghai Laboratory Animal Center (SLAC). Rats were housed in specific pathogen-free (SPF) facility with food and water provided ad libitum. The standard breeding protocol was followed and 34 newborn male rats from 16 mothers (two or three pups from each mother) were weighted at birth and divided at random into three groups: vacant plasmid group (VP, $\mathrm{n}=11$ ), low dose GLP-1 plasmid group (LG, $\mathrm{n}=12$ ) and high dose GLP-1 plasmid group (HG, $n=11)$. Electroporation was performed on the following day.

Aliquots of $120 \mu \mathrm{g}$ (HG group) or $60 \mu \mathrm{g}$ (LG group) sig-glp-1-pcDNA3 plasmid DNA and $120 \mu \mathrm{g}$ control pcDNA3 plasmid DNA (VP group) in $120 \mu \mathrm{l}$ phosphate-buffered saline were injected into the lateral side of left thigh of pups. Four electric pulses of $100 \mathrm{~V}$ at $50 \mathrm{~ms}$ followed by four more pulses of the opposite polarity were immediately delivered to the injected muscle. The electric pulse was delivered by an electric pulse generator (WJ-2002, Ningbo Scientz Biotechnology Co., Ltd).

Rats were maintained in specific pathogen-free facility following the standard protocol until 56 days of age. Weights of rats were recorded every two weeks and rats were weaned at day 21. As reported, plasmids may keep the expression ability for one month but the highest peak of expression is around 5-7 days after transfection (Aihara and Miyazaki 1998, Ataka et al. 2003). The whole leg muscle of five or six pups in each group was collected for confirming GLP-1 mRNA expression with RT-PCR using forward primer 5'-GCCAAGCTTA TGAAGACCGTTTACATCGTG-3' and reverse primer 5'-TATGGATCCTCATCCTCGGCCTTTCACC-3'

seven days after electroporation in our study. At 56 days of age, the remaining six rats in each group were weighed and euthanized by decapitation without fasting. Blood samples were collected just before sacrifice from carotid artery and sera were separated by centrifugation at $1300 \times \mathrm{g}$ at $4{ }^{\circ} \mathrm{C}$ for $15 \mathrm{~min}$ and stored at $-20{ }^{\circ} \mathrm{C}$ until insulin and glucose assay. Soleus and gastrocnemius were dissected and weighed, rapidly frozen in liquid nitrogen, then stored at $-80{ }^{\circ} \mathrm{C}$ until analysis.

The use and treatment of the animals followed the European Community Guidelines as accepted principles for the use of experimental animals. The animal experiment protocol was approved by the Animal Ethics Committee of Nanjing Agricultural University.

\section{Serum analysis}

Serum concentrations of insulin were measured in duplicate using commercially available ${ }^{125}$ I-RIA kit (Beijing Research Institute of Biotechnology, China) according to the manufacturer's guideline. The kit was validated for measuring murine serum samples and the detection limits were $2 \mu \mathrm{IU} / \mathrm{ml}$. The intra- and inter-assay coefficients of variation were $10 \%$ and $15 \%$, respectively.

Serum glucose concentrations were measured in duplicate using a commercial kit (Nanjing Jiancheng, Nanjing, China) according to the manufacturer's guideline.

\section{MyHC electrophoresis and analysis}

MyHC isoforms were separated using a modification of the SDS-polyacrylamide gel electrophoretic procedure developed by Talmadge and Roy (1993). Briefly, frozen muscles were minced with scissors in 9 volumes of ice-cold homogenization buffer (100 mM Na $\mathrm{P}_{2} \mathrm{O}_{4}, 0.3 \mathrm{mM} \mathrm{KCl}, 5 \mathrm{mM}$ EGTA, $5 \mathrm{mM}$ $\mathrm{MgCl}_{2}$ and $10 \mathrm{mM} \mathrm{DTT}$ ), and extracted for $30 \mathrm{~min}$ on ice, then centrifuged at $12000 \mathrm{~g}$ at $4{ }^{\circ} \mathrm{C}$. Protein content of the supernatant was estimated by Bradford assay. Samples were diluted in $2 \times$ loading buffer $(1 \%$ $\beta$-mercaptoethanol, $4 \%$ SDS, $20 \%$ glycerol, $0.2 \%$ bromophenol blue, and $1 \mathrm{M}$ Tris $\mathrm{pH}$ 6.8) to a final concentration of $0.5 \mathrm{mg} / \mathrm{ml} .2 \mu \mathrm{g}$ total protein was loaded on the gel (Stacking: $30 \%$ glycerol, $4 \%$ acrylamide:Bis (50:1), 70 mM Tris (pH 6.8), 4 mM EDTA, $0.4 \%$ SDS; Separating: $30 \%$ glycerol, $8 \%$ acrylamide:Bis (50:1), $0.2 \mathrm{M}$ Tris (pH 8.8), 0.1 M glycine, $0.4 \%$ SDS) prepared using the Bio-Rad Mini-Protein II system. Separate upper (0.1 M Tris, $150 \mathrm{mM}$ glycine, $0.1 \%$ SDS) and lower (50 mM Tris, $75 \mathrm{mM}$ glycine, $0.05 \%$ SDS) running buffers were used. The running conditions were $70 \mathrm{~V}$ (constant voltage) for $24 \mathrm{~h}$ at $4{ }^{\circ} \mathrm{C}$. The MyHC isoforms were visualized after staining with Coomasie brilliant blue.

Band densities were analyzed with Kodak Digital Science 1D software (Eastman Kodak Company Rochester, NY, USA). The ratio of each MyHC isoform density to the total was calculated to represent the proportion of each MyHC isoform.

\section{Measuring $m R N A$ expression by real-time PCR}

Total RNA were extracted from soleus and gastrocnemius with TRNzol total RNA Kit (Tiangen Biotech Co., Ltd, Beijing, China), according to the 
manufacturer's instruction. Total RNA concentration was then quantified by measuring the absorbance at $260 \mathrm{~nm}$ with a photometer (Eppendorf Biophotometer). Ratios of absorption (260/280 nm) of all preparations were between 1.9 and 2.1. $4.4 \mu \mathrm{g}$ of each RNA samples were subjected to electrophoresis through a $1.4 \%$ agarose formaldehyde gel to verify their integrity.

One microgram of total RNA was reverse transcribed by incubation at $37{ }^{\circ} \mathrm{C}$ for $1 \mathrm{~h}$ for the firststrand cDNA synthesis in a $25 \mu \mathrm{l}$ mixture consisting of $100 \mathrm{U}$ moloney murine leukemia virus (M-MLV) reverse transcriptase (Cat. No. M1701, Promega, Shanghai, China), 10 U RNase Inhibitor (Cat. No. N2611, Promega, Shanghai, China), $12 \mu \mathrm{M}$ random primers (6mer) (Cat. No. D3801, TAKARA Biotechnology (Dalian) Co., Ltd., China), $50 \mathrm{mM}$ Tris- $\mathrm{HCl}$ (pH 8.3), $10 \mathrm{mM} \mathrm{MgCl}_{2}, 50 \mathrm{mM}$ $\mathrm{KCl}, 10 \mathrm{mM}$ DTT, $0.5 \mathrm{mM}$ spermidine and $0.8 \mathrm{mM}$ each dNTP.

The synthesis of all primers was performed by Invitrogen Co. Shanghai, P. R. China. Real-time PCR was performed in Mx3000P (Stratagene, USA) with specific primers: MyHC I (NM-017240) F: 5'TTGCTCTACCCAACCCTAAGGATG-3', R: 5'-TTG TGTTTCTGCCT GAAGGTGC-3'; MyHC 2A (L13606) F: 5'-CTCAGGCTTCAAGATTTGGTGG-3', R: 5'-TTG TGCCTCTCTTCGGTCATTC-3'; MyHC 2X (XM-213 345) F: 5'-GGAGGAACAATCCAACGTCAACC-3', R: 5'-GGTCACTTTCCTGCTTTGGATCG-3'; MyHC IIB (NM-019325) F: 5'-TGAGCCAGACGGCACTGAA-3', R: 5'-GCTGCACTGTCTGGCCTTTG-3'; GLUT4 (NM012751) F: 5'-CGTTGGCATGGGTTTCCAG-3', R: 5'GCCTCTGGTTTCAGGCACTCTTAG-3'; PGC-1 $\alpha(A Y-$ 237127) F: 5'-CACTGACAGATGGAGCCGTGA-3', R: 5'-TGTTGGCTGGTGCCAGTAAGAG-3'; $\beta$-actin (NM007393) F: 5'-CCCTGTGCTGCTCACCGA-3', R: 5'ACAGTGTGGGTGACCCCGTC-3'. Mock RT and no template controls (NTC) were set to monitor the possible contamination of genomic DNA both at the stage of RT and RCR. The pooled sample made by mixing equal quantity of total RT products (cDNA) from all samples was used for optimizing the PCR condition and tailoring standard curve for each target gene, and melting curves were performed to ensure a single specific PCR product for each gene. $4 \mu \mathrm{l}$ of 40 -fold dilution of each RT product was used for PCR in a final volume of $25 \mu$ containing $0.4 \mu \mathrm{M}$ primers and $12.5 \mu \mathrm{l} \mathrm{SYBR}$ Green Real-time PCR Master Mix (Cat. No. QPK-201, TOYOBO Ltd., Japan).
Rodent $\beta$-actin was selected as reference gene. No marked difference of $\beta$-actin mRNA abundance was detected between groups. The $2^{-\Delta \Delta C t}$ method was used to analyze the real-time PCR data (Livak and Schmittgen 2001). The mRNA levels of LG and HG rats were expressed as the fold of change relative to the mean value of VP rats.

\section{Statistical analysis}

All data were presented as mean \pm S.E.M., and analyzed using one-way analysis of variance (ANOVA) or General Linear Model for multivariate with SPSS 11.0 for Windows. Differences were considered significant when $\mathrm{P}<0.05$.

\section{Results}

Detection of GLP-1 mRNA expression in muscles injected with sig-glp-1-pcDNA3

Seven days after transfection, muscles that underwent lectroporation were taken from rats of all groups (five or six pups in each group) and used for detection of GLP-1 mRNA expression with RT-PCR. No GLP-1 transcript was detected in VP rats, whereas clear bands of expected size for GLP-1 were seen in muscles of both LG and HG rats (Fig. 2A). It is interesting to note that low dose of GLP-1 plasmid transfection induced more abundant GLP-1 mRNA expression in the muscle compared to high dose of GLP-1 plasmid transfection.

Body weight, muscle weight, and pancreas weight

As shown in Figure 2B, LG treatment caused small yet significant growth retardation over the experimental period of 8 weeks $(\mathrm{P}<0.05)$, when the general effects of treatment and age on body weight were tested using General Linear Model for multivariate. Nevertheless, no alterations were found in soleus and gastrocnemius muscle weight or in pancreas weight (data not shown).

\section{Serum concentrations of insulin and glucose}

At 56 days of age, both LG and $\mathrm{HG}$ rats demonstrated significantly reduced serum insulin concentration (Fig. 2D) compared to VP rats $(\mathrm{P}<0.05)$. However, no alteration was detected in serum glucose concentrations (Fig. 2C). 
A

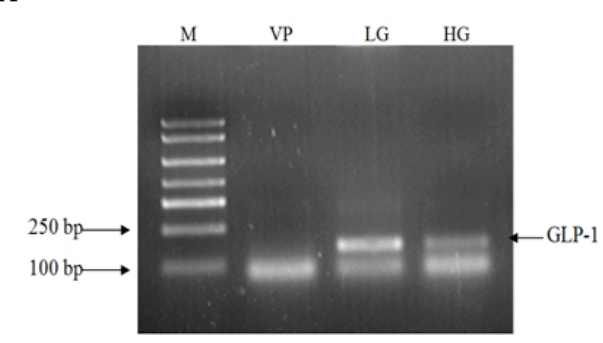

C

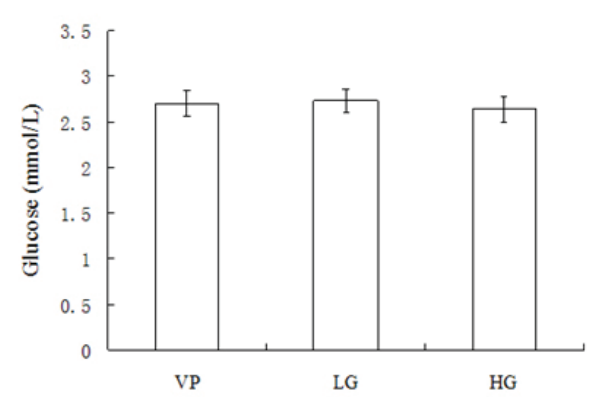

B

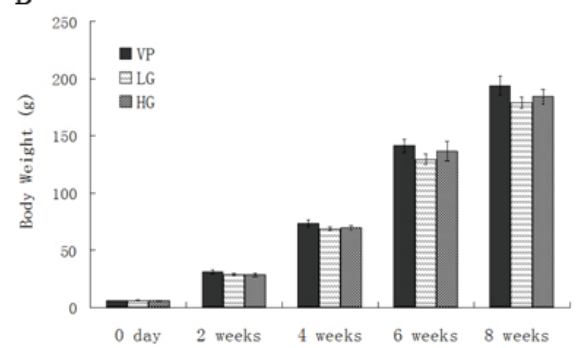

D

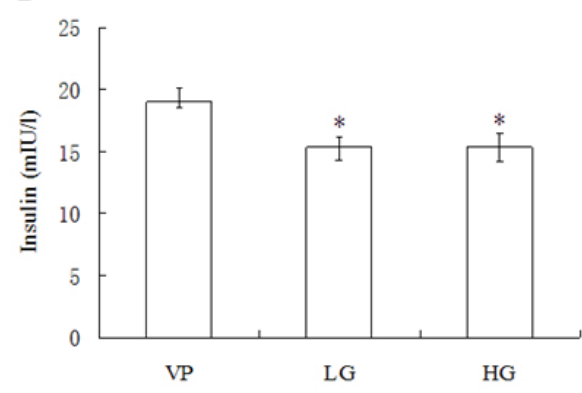

Fig. 2. Effect of neonatal GLP-1 plasmid transfection on postnatal growth and adult serum glucose and insulin concentrations in rats. (A) GLP-1 mRNA expression. Muscle samples were taken from 5-6 pups per group 7 days after transfection and pooled for detecting GLP-1 mRNA with RTPCR; (B) Body weight. Body weight was recorded every two weeks from day 0 to 8 weeks in rats of different groups. The general effects of treatment and age on body weight were tested by General Linear Model for multivariate with SPSS 11.0 for Windows; (C) Serum glucose concentration; (D) Serum insulin level. Blood samples were collected at 56 days of age from carotid artery when 6 rats per group were sacrificed. Values are means \pm S.E.M., $* P<0.05$ vs. VP, $\mathrm{n}=6$.

A

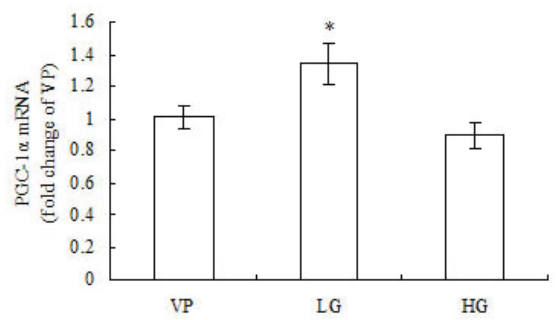

C

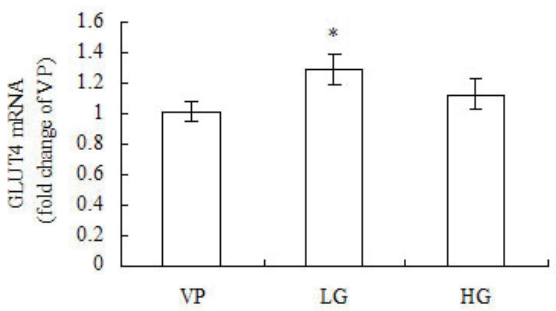

B

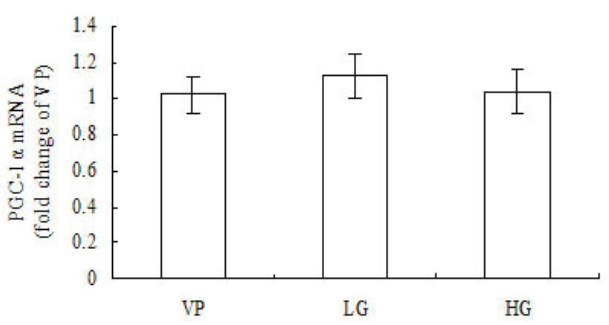

D

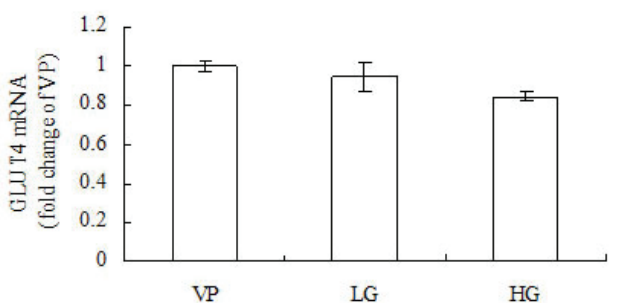

Fig. 3. Effect of neonatal GLP-1 plasmid transfection on expression of metabolic genes in skeletal muscle of rats. At 56 days of age, soleus and gastrocnemius muscles of six rats per group were collected after euthanasia. PGC- $1 \alpha$ mRNA expression in soleus (A) and gastrocnemius (B); GLUT4 mRNA expression in soleus (C) and gastrocnemius (D) were measured with real-time PCR. The method of $2^{-\Delta \Delta C t}$ was used to analyze the realtime PCR data. Values are means \pm S.E.M., $* P<0.05$ vs. VP, $\mathrm{n}=6$.

Expression of MyHC isoforms and metabolic genes in

A

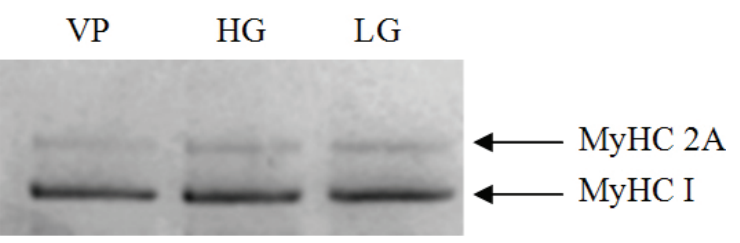
GLP-1 exposure were detected only in LG rats, in a muscle type-dependent manner. In soleus muscle, expression of PGC-1 $\alpha$ and GLUT4 mRNA was upregulated significantly in LG rats (Fig. 3). This was associated with increased MyHC IIB mRNA expression $(\mathrm{P}<0.05)$. In gastrocnemius muscle, no changes were detected at the level of transcription for all the genes studied. However, a MyHC type switch from IIB to I was observed at the level of protein expression in LG rats, as shown using SDS-PAGE (Table 1, Fig. 4).

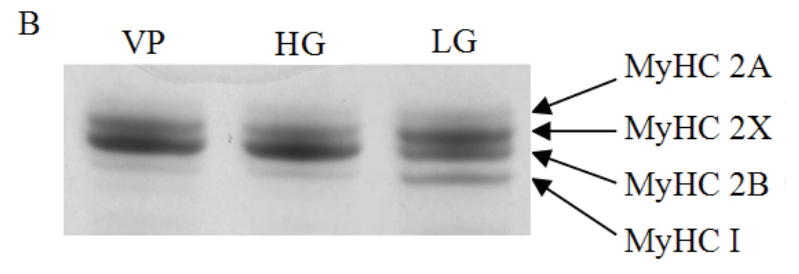

Fig. 4. Representative SDS-PAGE showing MyHC protein isoforms in soleus $(A)$ and gastrocnemius (B) muscle of 56-day-old rats. 
Table 1. Myosin heavy chain composition in soleus and gastrocnemius muscle of 8-week-old rats neonatally treated with GLP-1.

\begin{tabular}{lllccc}
\hline Muscle types & & MyHC isoforms & VP & LG & HG \\
\hline \multirow{2}{*}{ soleus } & mRNA & MyHC I & $1.02 \pm 0.09$ & $1.29 \pm 0.06$ & $1.04 \pm 0.22$ \\
& (fold change of & MyHC 2A & $1.01 \pm 0.16$ & $0.78 \pm 0.14$ & $0.74 \pm 0.11$ \\
& control) & MyHC 2X & $1.06 \pm 0.17$ & $0.94 \pm 0.23$ & $1.06 \pm 0.12$ \\
& & MyHC 2B & $1.00 \pm 0.02$ & $1.25 \pm 0.07^{*}$ & $0.92 \pm 0.12$ \\
& Protein (\%) & MyHC I & $81.0 \pm 2.5$ & $85.5 \pm 2.3$ & $82.3 \pm 0.8$ \\
& & MyHC 2A & $19.0 \pm 2.5$ & $14.4 \pm 2.3$ & $17.7 \pm 0.8$ \\
gastrocnemius & mRNA & MyHC I & $1.07 \pm 0.20$ & $1.08 \pm 0.15$ & $0.69 \pm 0.17$ \\
& (fold change of & MyHC 2A & $1.05 \pm 0.16$ & $1.21 \pm 0.23$ & $0.93 \pm 0.16$ \\
& control) & MyHC 2X & $1.00 \pm 0.04$ & $0.99 \pm 0.06$ & $0.99 \pm 0.09$ \\
& & MyHC 2B & $1.00 \pm 0.21$ & $0.82 \pm 0.10$ & $0.90 \pm 0.21$ \\
& Protein (\%) & MyHC I & $5.3 \pm 2.2$ & $16.7 \pm 2.1 *$ & $6.0 \pm 3.8$ \\
& & MyHC 2A/2X & $30.7 \pm 1.6$ & $42.0 \pm 3.8$ & $26.8 \pm 8.1$ \\
& & MyHC 2B & $64.0 \pm 2.6$ & $41.3 \pm 5.3 *$ & $67.2 \pm 11.6$ \\
\hline
\end{tabular}

At 56 days of age, soleus and gastrocnemius muscles of all rats were collected for detection of mRNA and protein levels of MyHCs using real-time PCR and SDS-PAGE, respectively. The $2^{-\Delta \Lambda C t}$ method was used to analyze the real-time PCR data, and the results were expressed as the fold of change relative to the mean value of VP rats. Results of SDS-PAGE are shown as percentage of each MyHC isoform. * $P<0.05 \mathrm{vs} . \mathrm{VP}, \mathrm{n}=6$.

\section{Discussion}

"Gene therapy" approach has been used in preclinical studies for sustained therapeutic delivery of GLP-1R agonists. Systemic delivery of a GLP-1 minigene via an adenovirus improved plasma glucose homeostasis in both $\mathrm{db} / \mathrm{db}$ mice and Zucker Diabetic Fatty (ZDF) rats (Parsons et al. 2007). Similarly, intramuscular injection of a hybrid cDNA encoding a GLP-1/Fc peptide normalized glucose tolerance by enhancing insulin secretion and suppressing glucagon release in $\mathrm{db} / \mathrm{db}$ mice (Kumar et al. 2007). Delivery of GLP-1 via an adenoviral vector (Ad-GLP-1) was highly effective in controlling blood glucose in ob/ob mice. Ad-GLP-1 normalized blood glucose, improved $\beta$-cell function and insulin sensitivity and reduced hepatic glucose production (Lee et al. 2007). In our study a classic eukaryotic expression vector pcDNA3 was used for secretory GLP-1 expression, and robust expression of GLP-1 mRNA was detected in the muscle seven days after transfection.

It may be surprising that $\mathrm{LG}$ rats that received a low dose $(60 \mu \mathrm{g})$ of plasmid DNA actually expressed higher GLP-1 mRNA, compared to those transfected with a high dose $(120 \mu \mathrm{g})$. Actually, expression efficiency does not always correlate positively with the amount of plasmid transfected, as it is affected by numerous factors including species, age of animal, type of tissue, etc. Previous studies used 50-100 $\mu \mathrm{g}$ of plasmid DNA for intramuscular transfection in mice (Samakoglu et al. 2001, Blomberg et al. 2002), and more than $100 \mu \mathrm{g}$ of plasmid DNA were needed for adult rats (Watanabe et al. 2001). In the present study, higher expression efficiency was achieved with $60 \mu \mathrm{g}$ of plasmid DNA in 2-day-old rat pups.

We observed significant growth retardation in LG group with higher ectopic GLP-1 expression in the muscle. Rats in HG group were also smaller compared to VP rats, but the difference did not reach statistical significance. This finding was in agreement with the previous report that daily subcutaneously injection of Ex-4 during the first 6 days after birth caused significantly lower body weight in both intrauterine growth retarded (IUGR) and control Sprague-Dawley (SD) rats from two weeks of age through adulthood (Stoffers et al. 2003). However, the effects of neonatal treatment with GLP-1 or its analogs on animal growth are not consistent. Spontaneously diabetic GK rats (Tourrel et al. 2002) and streptozotocin (STZ)-induced diabetic rats (Tourrel et al. 2001) did not show body weight 
reduction in response to neonatal treatment with GLP-1 or Ex-4. Since GK rats and STZ-induced diabetic rats share the common feature of severely impaired insulin secretion, it is possible that the growth retardation caused by neonatal GLP-1 is mediated by alterations in serum insulin concentration.

In the present study, the growth retardation was accompanied by significantly reduced serum insulin concentration. This contradicts the widely accepted opinion that GLP-1 or exendin-4 are potent secretogogues of insulin (D'Alessioo et al. 1994, MacDonald et al. 2002, Bai et al. 2005). However, it has to be mentioned that the insulinotropic capacity of neonatal GLP-1 is seen mostly in diabetic models. Our results indicate an opposite effect of neonatal GLP-1 on adult serum insulin levels in healthy rats. Interestingly, despite reduced serum insulin concentration, blood glucose levels were maintained stable in the present study. This is in agreement with the previous report showing unaltered fasting blood glucose in adult SD rats neonatally treated with exendin-4 (Stoffers et al. 2003). The ability to maintain glucose homeostasis under the conditions of reduced insulin level may imply increased insulin sensitivity in peripheral tissues (Gedulin et al. 2005).

Skeletal muscle is one of the most important target tissues for insulin action and it plays an important role in the regulation of glucose homeostasis. Increased insulin sensitivity in skeletal muscle would mean enhanced glucose uptake and utilization (Lee et al. 2007). It is well known that the metabolic properties of skeletal muscle are closely associated with myofiber type composition (Zierath and Hawley 2004). Muscles located in different part of the body exhibit different myofiber type composition, i.e. different percentages of four major myofiber types with type-specific expression of the corresponding myosin heavy chain (MyHC) isoforms (Rivero et al. 1998), namely slow-oxidative type I, fastoxidative type IIA, fast oxidative-glycolytic type IIX and fast-glycolytic type IIB. We demonstrated, for the first time, muscle type-dependent effects of neonatal GLP-1 on MyHC isoform composition and metabolic gene expression. Slow-oxidative soleus muscle of $\mathrm{LG}$ rats demonstrated significantly increased PGC- $1 \alpha$ and GLUT4 mRNA expression, implying increased oxidative capacity, whereas fast-glycolytic gastrocnemius muscle of LG rats showed a MyHC type switch from IIB to I, indicating increased glucose uptake and improved insulin sensitivity, which contributes to the maintenance of glucose homeostasis. Nevertheless, as the function of genes is determined by its protein rather than mRNA, and the steady-state mRNA levels are not always in line with protein contents, it awaits further investigation whether PGC- $1 \alpha$ and GLUT4 are also increased at the level of protein in soleus muscle of LG rats.

The mechanism by which neonatal GLP-1 affects gene expression of adult skeletal muscle is not clear. Since there is still a controversy with respect to GLP-1 receptor expression in skeletal muscle, we can only speculate that GLP-1 may act directly on skeletal muscle via $\mathrm{PI} \mathrm{K} / \mathrm{PKB}$ and MAPKs pathways (Acitores et al. 2004), to program the metabolic characteristics, or indirectly through insulin action, as previous studies hinted a link between MyHC composition and insulin concentration (Oberbach et al. 2006, Venojarvi et al. 2008).

In conclusion, the present study provided evidences that neonatal exposure of healthy pups to ectopic overexpression of GLP-1 causes growth retardation with decreased serum insulin, as well as muscle type-dependent modifications in MyHC type composition and metabolic gene expression in adult rats.

\section{Conflict of Interest}

There is no conflict of interest.

\section{Acknowledgements}

This work was supported by National Basic Research Program of China (2004CB117505).

\section{References}

ACITORES A, GONZALEZ N, SANCHO V, VALVERDE I, VILLANUEVA-PENACARRILLO ML: Cell signalling of glucagon-like peptide-1 action in rat skeletal muscle. J Endocrinol 180: 389-398, 2004.

AIHARA H, MIYAZAKI J: Gene transfer into muscle by electroporation in vivo. Nat Biotechnol 16: 867-870, 1998.

ATAKA K, MARUYAMA H, NEICHI T, MIYAZAKI J, GEJYO F: Effects of erythropoietin-gene electrotransfer in rats with adenine-induced renal failure. Am J Nephrol 23: 315-323, 2003.

AULINGER B, D'ALESSIO D: Glucagon-like peptide 1: continued advances, new targets and expanding promise as a model therapeutic. Curr Opin Endocrinol Diabetes Obes 14: 68-73, 2007. 
BAI L, MEREDITH G, TUCH BE: Glucagon-like peptide-1 enhances production of insulin in insulin-producing cells derived from mouse embryonic stem cells. J Endocrinol 186: 343-352, 2005.

BLOMBERG P, ESKANDARPOUR M, XIA S, SYLVEN C, ISLAM KB: Electroporation in combination with a plasmid vector containing SV40 enhancer elements results in increased and persistent gene expression in mouse muscle. Biochem Biophys Res Commun 298: 505-510, 2002.

D'ALESSIO DA, KAHN SE, LEUSNER CR, ENSINCK JW: Glucagon-like peptide 1 enhances glucose tolerance both by stimulation of insulin release and by increasing insulin-independent glucose disposal. $J$ Clin Invest 93: 2263-2266, 1994.

GEDULIN BR, NIKOULINA SE, SMITH PA, GEDULIN G, NIELSEN LL, BARON AD, PARKES DG, YOUNG AA: Exenatide (exendin-4) improves insulin sensitivity and $\beta$-cell mass in insulin-resistant obese fa/fa Zucker rats independent of glycemia and body weight. Endocrinology 146: 2069-2076, 2005.

HOLNESS MJ, LANGDOWN ML, SUGDEN MC: Early-life programming of susceptibility to dysregulation of glucose metabolism and the development of type 2 diabetes mellitus. Biochem J 349: 657-665, 2000.

KASHIMA Y, MIKI T, SHIBASAKI T, OZAKI N, MIYAZAKI M, YANO H, SEINO S: Critical role of cAMPGEFII--Rim2 complex in incretin-potentiated insulin secretion. J Biol Chem 276: 6046-6053, 2001.

KIM JG, BAGGIO LL, BRIDON DP, CASTAIGNE JP, ROBITAILLE MF, JETTE L, BENQUET C, DRUCKER DJ: Development and characterization of a glucagon-like peptide 1-albumin conjugate: the ability to activate the glucagon-like peptide 1 receptor in vivo. Diabetes 52: 751-759, 2003.

KNAUF C, CANI PD, PERRIN C, IGLESIAS MA, MAURY JF, BERNARD E, BENHAMED F, GREMEAUX T, DRUCKER DJ, KAHN CR, GIRARD J, TANTI JF, DELZENNE NM, POSTIC C, BURCELIN R: Brain glucagon-like peptide-1 increases insulin secretion and muscle insulin resistance to favor hepatic glycogen storage. J Clin Invest 115: 3554-3563, 2005.

KUMAR M, HUNAG Y, GLINKA Y, PRUD'HOMME GJ, WANG Q: Gene therapy of diabetes using a novel GLP1/IgG1-Fc fusion construct normalizes glucose levels in db/db mice. Gene Ther 14: 162-172, 2007.

LEE YS, SHIN S, SHIGIHARA T, HAHM E, LIU MJ, HAN J, YOON JW, JUN HS: Glucagon-like peptide-1 gene therapy in obese diabetic mice results in long-term cure of diabetes by improving insulin sensitivity and reducing hepatic gluconeogenesis. Diabetes 56: 1671-1679, 2007.

LIVAK KJ, SCHMITTGEN TD: Analysis of relative gene expression data using real-time quantitative PCR and the $2^{-\triangle \Delta C t}$ method. Methods 25: 402-408, 2001.

LUQUE MA, GONZALEZ N, MARQUEZ L, ACITORES A, REDONDO A, MORALES M, VALVERDE I, VILLANUEVA-PENACARRILLO ML: Glucagon-like peptide-1 (GLP-1) and glucose metabolism in human myocytes. $J$ Endocrinol 173: 465-473, 2002.

MACDONALD PE, EL-KHOLY W, RIEDEL MJ, SALAPATEK AM, LIGHT PE, WHEELER MB: The multiple actions of GLP-1 on the process of glucose-stimulated insulin secretion. Diabetes 51 (Suppl 3): S434-S442, 2002.

MALLINSON JE, SCULLEY DV, CRAIGON J, PLANT R, LANGLEY-EVANS SC, BRAMELD JM: Fetal exposure to a maternal low-protein diet during mid-gestation results in muscle-specific effects on fiber type composition in young rats. Br J Nutr 98: 292-299, 2007.

OBERBACH A, BOSSENZ Y, LEHMANN S, NIEBAUER J, ADAMS V, PASCHKE R, SCHON MR, BLUHER M, PUNKT K: Altered fiber distribution and fiber-specific glycolytic and oxidative enzyme activity in skeletal muscle of patients with type 2 diabetes. Diabetes Care 29: 895-900, 2006.

PARSONS GB, SOUZA DW, WU H, YU D, WADSWORTH SG, GREGORY RJ, ARMENTANO D: Ectopic expression of glucagon-like peptide 1 for gene therapy of type II diabetes. Gene Ther 14: 38-48, 2007.

RIVERO JL, TALMADGE RJ, EDGERTON VR: Fibre size and metabolic properties of myosin heavy chain-based fibre types in rat skeletal muscle. J Muscle Res Cell Motil 19: 733-742, 1998.

SAMAKOGLU S, FATTORI E, LAMARTINA S, TONIATTI C, STOCKHOLM D, HEARD JM, BOHL D: $\beta$ Minorglobin messenger RNA accumulation in reticulocytes governs improved erythropoiesis in beta thalassemic mice after erythropoietin complementary DNA electrotransfer in muscles. Blood 97: 2213-2220, 2001.

SINACORE DR, GULVE EA: The role of skeletal muscle in glucose transport, glucose homeostasis, and insulin resistance: implications for physical therapy. Phys Ther 73: 878-891, 1993. 
STOFFERS DA, DESAI BM, DELEON DD, SIMMONS RA: Neonatal exendin-4 prevents the development of diabetes in the intrauterine growth retarded rat. Diabetes 52: 734-740, 2003.

TALMADGE RJ, ROY RR: Electrophoretic separation of rat skeletal muscle myosin heavy-chain isoforms. $J$ Appl Physiol 75: 2337-2340, 1993.

TOFT-NIELSEN MB, DAMHOLT MB, MADSBAD S, HILSTED LM, HUGHES TE, MICHELSEN BK, HOLST JJ: Determinants of the impaired secretion of glucagon-like peptide-1 in type 2 diabetic patients. $J$ Clin Endocrinol Metab 86: 3717-3723, 2001.

TOURREL C, BAIBE D, MEILE MJ, KERGOAT M, PORTHA B: Glucagon-like peptide-1 and exendin-4 stimulate beta-cell neogenesis in streptozotocin-treated newborn rats resulting in persistently improved glucose homeostasis at adult age. Diabetes 50: 1562-1570, 2001.

TOURREL C, BAILBE D, LACORNE M, MEILE MJ, KERGOAT M, PORTHA B: Persistent improvement of type 2 diabetes in the Goto-Kakizaki rat model by expansion of the beta-cell mass during the prediabetic period with glucagon-like peptide-1 or exendin-4. Diabetes 51: 1443-1452, 2002.

VENOJARVI M, AUNOLA S, PUHKE R, MARNIEMI J, HAMALAINEN H, HALONEN JP, LINDSTROM J, RASTAS M, HALLSTEN K, NUUTILA P, HANNINEN O, ATALAY M: Exercise training with dietary counselling increases mitochondrial chaperone expression in middle-aged subjects with impaired glucose tolerance. BMC Endocr Disord 8: 3, 2008.

WATANABE K, NAKAZAWA M, FUSE K, HANAWA H, KODAMA M, AIZAWA Y, OHNUKI T, GEJYO F, MARUYAMA H, MIYAZAKI J: Protection against autoimmune myocarditis by gene transfer of interleukin10 by electroporation. Circulation 104: 1098-1100, 2001.

XU G, STOFFERS DA, HABENER JF, BONNER-WEIR S: Exendin-4 stimulates both beta-cell replication and neogenesis, resulting in increased beta-cell mass and improved glucose tolerance in diabetic rats. Diabetes 48 : 2270-2276, 1999.

ZIERATH JR, HAWLEY JA: Skeletal muscle fiber type: influence on contractile and metabolic properties. PLoS Biol 2: 1523-1527, 2004. 